\title{
Museo Nacional Amazónico: una deuda pendiente
}

\author{
Amazonian National Museum: an outstanding debt
}

Ana María Lebrún Aspíllaga ${ }^{1}$

\section{RESUMEN}

El Museo Nacional Amazónico se plantea como un espacio cultural público de la región y como un referente para el conocimiento y comprensión de la Amazonía, de los recursos naturales, la geografía, las expresiones culturales propias de cada comunidad amazónica, la historia y de sus ciudades.

El museo promueve la investigación, conservación, educación, exhibición y difusión de patrimonio natural y cultural, material e inmaterial, en su contexto original. Se concibe como una institución de carácter nacional y repercusión internacional.

Este espacio cultural será un espacio dedicado a la gran riqueza y diversidad natural y cultural de la Amazonía Peruana. La colección se compone de bienes arqueológicos, históricos, de ciencias naturales, etnográficos, artísticos, fotográficos, documentales, entre otros, los mismos que contarán con un proceso de conservación preventiva, tanto de origen orgánico como inorgánico y un programa de conservación y restauración para todos los tipos de piezas.

Un aspecto de especial relevancia es generar una estrecha relación con las instituciones educativas, desde un enfoque pedagógico e intercultural, teniendo en cuenta que este llegue a ser un apoyo para el profesor en la tarea educativa. Los programas deben ser dirigidos, estructurados $y$, en concordancia con los diseños curriculares de las instituciones educativas, que facilite el aprendizaje formal, siendo la exposición el canal conductor para reforzar o apoyar los conocimientos adquiridos en clase.

\section{Palabras clave}

Museo Nacional Amazónico, Amazonía, Interculturalidad, Diversidad Cultural, Educación Museo Nacional Amazónico.

\section{ABSTRACT}

The Amazonian National Museum was intended to be a public cultural space in the region and a reference spot for the knowledge and understanding of the Amazonia, the natural resources, geography, and cultural expressions specific to each Amazonian community, their history and cities.

The museum promoted the research, conservation, education, exhibition and dissemination of tangible and intangible, natural and cultural heritage in their original context. It was designed as an institution of national level and international relevance.

This cultural space was devoted to the great natural and cultural richness and diversity of the Peruvian Amazonia. The collection comprised archeological, historic, natural, ethnographic, artistic, photographic, documentary items, among others. All of them would

\footnotetext{
1 Arquitecta. Magíster en Museología. Directora de la carrera de Arquitectura y Diseño de Interiores de la Universidad Privada del Norte - Sede Comas. Past Directora de Museos y Gestión del Patrimonio Histórico del Instituto Nacional de Cultura y del Museo Postal y Filatélico del Perú. Gerente General de RUTA 4 SAC Planificación y Acción Cultural. Vicepresidenta y Directora de Proyectos Nacionales e Internacionales de Instituto RUTA 4 Investigación y Proyectos.
} 
be subject to preventive preservation measures, both organic and non-organic, and would be included in a preservation and restoration program for all kind of pieces.

Another aspect of particular relevance was the generation of a strong bond with the educational institutions under an intercultural and pedagogical approach, so that the Museum could be a supporting resource for the teacher during the educational process. The programs should be structured and aligned with the curriculum design of the educational institution so as to facilitate formal learning, with the exhibition being the canal to reinforce or support the knowledge gained in class.

\section{Keywords}

The Amazonian National Museum, Amazon, Interculturality, Cultural Diversity, Education The Amazonian National Museum (Education).

\section{Introducción}

El Museo Nacional Amazónico 2 es un espacio cultural contemporáneo que se presenta como un lugar para la convergencia de pobladores locales, así como de turistas nacionales $y$ extranjeros de todas las edades, en un ambiente que propicia la interculturalidad y que promueve la sensibilización respecto a la protección de las expresiones culturales propias de ese ámbito. En este sentido, la apuesta por la difusión del conocimiento y la investigación científica son ejes fundamentales en el funcionamiento de este museo.

El Museo Nacional Amazónico se presenta como el más importante espacio cultural público de la región y como un referente para el conocimiento y comprensión de la Amazonía, de los recursos naturales, de la geografía, de las expresiones culturales propias de cada comunidad amazónica, de la historia y de sus ciudades. Al mismo tiempo, se presenta como un espacio para la apropiación y fortalecimiento de identidades locales y para la reivindicación de los diferentes y diversos grupos culturales de la Amazonía peruana, de manera que estos puedan sentirse no solamente representados en el museo sino también puedan percibirlo como un espacio propio desde el cual se difunden sus manifestaciones artísticas.
El museo tiene una tarea importante de cara a la sociedad en general, debido a que es mediado entre el público y las obras que se presentan, permitiendo explicar y difundir el valor de las manifestaciones artísticas, culturales, ambientales, entre otras que en muchos casos no son abordados en las escuelas $y / 0$ instituciones educativas. Igualmente, el Museo Nacional Amazónico, como espacio contemporáneo se proyecta al futuro, y se plantea como un espacio versátil, factible de transformación, dedicado al ser humano, además a la exhibición de bienes materiales, a la difusión del patrimonio inmaterial y de la cultura viva de toda la región. Esta proyección implica también el futuro crecimiento del museo en términos de infraestructura, colección, personal, usuarios y servicios.

El objetivo general del Museo Nacional Amazónico es adquirir, conservar, estudiar, exponer y difundir el patrimonio material $e$ inmaterial de la Amazonía peruana con fines de estudio, educación y recreo, a través de un enfoque intercultural y pedagógico, alentando el desarrollo de la diversidad cultural, la didáctica y la interacción. Asimismo, se velará por un trabajo transdisciplinario para la preservación del medio ambiente y de las comunidades nativas, dentro del contexto de globalización e intercambio cultural mundial.

2 La propuesta del Museo Nacional Amazónico ha sido realizada por un equipo de profesionales integrados por: Mg. Virgilio Freddy Cabanillas Delgadillo, Arq. Elena Molina Cerpa, Lic. Teresa Arias Rojas, Hist. María Belén Soria Casaverde, Arqueol. Julio Abanto Llaque, Lic. Jessica Morote Guevara, Lic. Mónica Villanueva Galdós, Lic. Alex Criado Dávila, Lic. Victoria Ávalos Carrillo y Mg. Ana Maria Lebrún Aspíllaga. 


\section{Conceptualización del Museo Nacional Amazónico}

La Amazonía es para el mundo la reserva más importante para el futuro, porque en ella se encuentra la mayor diversidad natural y cultural de todo el planeta. En el Perú, esta región representa más del $62 \%$ de nuestro territorio $y$ en ella existen numerosas comunidades indígenas de diferente raíz cultural. La región amazónica cuenta con una diversidad de riqueza, potencial turístico y cultural única en el mundo; además, demanda la necesidad mundial de protección, de ser un destino importante para la investigación que propicie su conocimiento, conservación y difusión, en una dimensión coherente con la magnitud de la importancia que representa su conservación para nuestro país y para el mundo.

El Museo Nacional Amazónico, como espacio físico integrado a su entorno paisajístico natural y cultural, servirá como espacio de convergencia de las comunidades indígenas, la población local y los turistas, así como los visitantes en general, promoviendo la convivencia entre personas y demás especies vivas en un entorno de diversidad.

Es un museo que promueve la investigación, conservación, educación, exhibición y difusión de patrimonio natural y cultural, material $e$ inmaterial en su contexto original.

No es posible encasillar el museo en una sola tipología de museo, conociendo la complejidad de todos los aspectos que involucra su conceptualización. Se trata de una institución de carácter nacional con repercusión internacional que a su vez debe mantener una presencia importante en la comunidad local hasta lograr un grado de apropiación que lo constituya en un espacio comunitario de integración nacional. Además, al mismo tiempo se aborda la temática cultural, natural y biológica, así como la preservación y difusión del patrimonio histórico y la difusión de la cultura viva, del patrimonio tangible $e$ intangible, incorporando en su discurso y contenidos a las comunidades nativas y a las zonas urbanas. Por lo tanto, se puede decir que el museo se plantea de la siguiente manera:
- Según su temática y su colección es un museo regional.

- Según el impacto proyectado es un museo nacional e internacional.

- Según su manejo y propuesta operativa es un museo sostenible (social, medio ambiental económico y cultural).

- Según sus líneas estratégicas es un museo comunitario y participativo.

- Según los recursos museográficos planteados es un museo dinámico $e$ interactivo.

- Según su arquitectura es un museo contemporáneo y contextualista.

El mandato del Museo Nacional Amazónico es la arqueología, las ciencias naturales y la historia de los habitantes de la Amazonía, desde los inicios de su ocupación hasta nuestros días.

El Museo Nacional Amazónico se proyecta como una institución museística dinámica, con un predominante papel social $e$ intercultural para integrar a sus habitantes, con una actitud crítica potenciando la comunicación, ya que el público dejará de ser el espectador para ser el actor principal, existirá un diálogo entre el público y el museo.

El público objetivo del Museo Nacional Amazónico será variable, asimismo el público potencial del museo es una sumatoria del público potencial escolar, familiar y turístico, es decir todo segmento de la población local, regional, nacional e internacional.

Los beneficiarios directos del Museo Nacional Amazónico serán los pobladores de Iquitos, las comunidades indígenas y los turistas nacionales y extranjeros. Asimismo, los beneficiarios indirectos estarán conformados por la población de la Amazonía en general, donde se considera a la población urbana y nativa, y los investigadores nacionales y extranjeros.

Las líneas temáticas planteadas por el MINCUL (2013) se encuentra basado en umbrales y 
acontecimientos, los umbrales cuentan con tres temáticas que son: el origen de la Amazonía, diversidad ambiental y cultural en la Amazonía andina y los procesos históricos; asimismo los acontecimientos están basados en: el cambio climático, redes de intercambio, relación andesAmazonía, cuenca del Amazonas, Iquitos, el extractivismo, la diáspora del pueblo kukamakukamiria y etnociencia o conocimiento tradicional.

El Museo Nacional Amazónico se plantea como un espacio dedicado a la gran riqueza y diversidad natural y cultural de la Amazonía Peruana, para ello, la colección del museo se compone por bienes arqueológicos, históricos, de ciencias naturales, etnográficos, artísticos, fotográficos, documentales, entre otros, los mismos que contarán con un proceso de conservación preventiva, tanto de origen orgánico como inorgánico y un programa de conservación y restauración para todos los tipos de piezas. Igualmente, los depósitos contarán con los controles respectivos de humedad relativa y temperatura que serán implementados con la más reciente tecnología.

Asimismo, cabe precisar que el Ministerio de Cultura debe apoyar al artista local y de la Amazonía en general para que puedan exponer sus obras en las instalaciones del museo.

\section{Plan de adquisiciones de material cultural}

El Museo Nacional Amazónico manejará un plan de adquisiciones acorde con las colecciones conformadas y la proyección de la creación de nuevas colecciones. Este plan se basará principalmente en planificar el incremento de las colecciones en base a las siguientes propuestas:

\section{- Compra directa.}

- Buenas prácticas orientadas hacia la población en general para que entreguen de manera voluntaria material cultural que posean.

- Alentar las donaciones de los poseedores de bienes culturales de la nación.
- Legado de material cultural.

- Búsqueda de patrocinadores para adquirir colecciones existentes y que no quieran ser donadas voluntariamente.

- El depósito de material cultural, fruto de un contrato en el que uno de los contratantes recibe del otro un bien mueble con obligación de conservarlo, custodiarlo o restituirlo cuando le sea reclamado.

- El intercambio o permuta, en el cual cada uno de los contratantes se obliga a dar una cosa para recibir otra, y se perfila con más interés de cara al futuro, debido a que en la actualidad apenas lo utiliza. Para este caso, tendría que existir una ley que lo contemple.

- Creación de un comité especial con personal del museo para que se encargue de solicitar fondos de carácter social para la adquisición de bienes para el museo.

- Producción de fondos propios obtenidos a partir de metas didácticas o como apoyo a una exposición, o destinados al centro de documentación del museo, entre otras.

- Otras formas de adquisición son: las prospecciones etnológicas, prospecciones arqueológicas, excavaciones arqueológicas, hallazgos casuales, recolección, decomiso, dación, expropiación, premios, entre otros.

\section{Planes, programas, proyectos y actividades para la investigación, exposición y la gestión educativa}

El Museo Nacional Amazónico contará con programas permanentes relacionados con la investigación, conservación y difusión de las colecciones, para ello se desarrollarán planes, programas de voluntariado con instituciones públicas y privadas; programas de investigación a través de convenios con universidades $e$ instituciones de educación superior; programas de exposiciones permanentes, temporales e 
itinerantes; programas educativos a través de convenios con colegios, institutos técnicos y universidades.

El Museo Nacional Amazónico promoverá la investigación en temas relacionados con la región amazónica, generando espacios propicios para este fin $y$ facilitando la información y las condiciones adecuadas para investigadores nacionales $e$ internacionales, teniendo en cuenta el Código de Deontología del ICOM para museos, institución que fomenta la investigación en los museos. Es así que el Museo Nacional Amazónico, como institución museística, deberá considerar necesariamente la investigación como una de sus actividades permanentes. Asimismo, se promoverá la publicación y difusión de las investigaciones realizadas para el conocimiento del público en general y para investigadores, tales como referencias bibliográficas de futuras investigaciones, generando con esto un ciclo permanente para la producción de conocimiento.

Para la realización de la investigación en el museo, se realizarán alianzas estratégicas con diversas instituciones que se encuentran ubicadas en la región Amazónica, asimismo con instituciones que realicen investigación en la Amazonía, tanto de carácter nacional e internacional, asimismo se realizarán trabajos en conjunto para la gestión de convenios interinstitucionales con diversas instituciones públicas y privadas de toda índole.

El Museo Nacional Amazónico propiciará el estudio de sus colecciones a través de diversos programas y convenios con instituciones educativas. El estudio de las piezas integrantes de la colección deberá ser permanente y deberá ir de la mano con los procesos de conservación preventiva, conservación y restauración, así como con los procesos de nuevas adquisiciones del museo.

La propuesta del Museo Nacional Amazónico plantea contar con una exposición permanente acorde con las áreas temáticas abordadas, las mismas que serán renovadas cada 5 a 8 años, tomándose en consideración las evaluaciones periódicas que se realice como política del museo. También se contará con áreas de exposición temporal cuya programación será manejada por la administración y será coherente con la política del museo, estas deberán renovarse cada por semanas o meses de acuerdo con la programación anual del museo.

El museo contará igualmente con áreas de exposición al aire libre con diversas temáticas que tendrán una duración de acuerdo a la política del museo.

Finalmente, las exposiciones itinerantes se desarrollarán en diversas instituciones educativas de nivel primario, secundario, técnico y/o universitario, así como en instituciones públicas y privadas, gestionadas por el museo en concordancia con la política de fortalecimiento de la identidad cultural amazónica.

Se expondrá de manera didáctica el nivel de desarrollo alcanzado en la Amazonía y por las comunidades indígenas en sus aspectos de organización socio-política, tecnología, arte y cosmovisión.

El enfoque pedagógico e intercultural del Museo Nacional Amazónico de proyección hacia la sociedad permite incidir en la educación principalmente de los niños y adolescentes en edad escolar desarrollando las habilidades de los estudiantes y público en general para comprender y apreciar el arte, el patrimonio cultural y natural y la historia Amazónica, a partir de un enfoque pedagógico e intercultural. Esto implica un conocimiento de las teorías y concepciones del arte, y la habilidad tanto para reaccionar ante el arte como para crearlo. Además de incidir en la educación patrimonial y en la cultura visual.

La importancia que va a generar el proyecto en el museo permitirá que, los estudiantes de escuelas primarias y secundarias, estudiantes de instituciones técnicas $y$ universidades, así como los adultos, adultos mayores y discapacitados se involucren con la región Amazónica, y con la diversidad 
natural y cultural existente. Se logrará que, de esta manera, se sientan identificados con la cultura amazónica, sus historias, sus mitos y leyendas, entre otros; accedan a una oferta educativa dirigida a los adultos, a adultos mayores, a familias acompañadas por sus hijos, a grupos específicos o a "nuevo público", tales como profesionales, miembros de asociaciones diversas, amas de casa, grupos juveniles, militares, grupos marginales, entre otros.

El impacto que va a generar a toda la región Amazónica será la de revalorar su cultura y hacerla conocida a todo el Perú y el mundo, debido al arraigo cultural de los pueblos indígenas que se desarrollaron en la Amazonía.

\section{Programas educativos en el museo}

La importancia y necesidad del museo es generar una estrecha relación con las instituciones educativas, desde un enfoque pedagógico e intercultural, teniendo en cuenta que llegue a ser un apoyo para el profesor en la tarea educativa. Los programas deben ser dirigidos, estructurados $y$ en concordancia con los diseños curriculares de las instituciones educativas para facilitar el aprendizaje formal, y sea la exposición un canal conductor capaz de reforzar o apoyar los conocimientos adquiridos en clase.

Cada programa cultural se inicia por alguna razón determinada y se concibe para un público concreto, cuyas necesidades, intereses, destrezas y experiencias se conocen previamente para tenerlas en cuenta a la hora de definir los objetivos, contenidos, metodología, materiales didácticos, agente educativo, tipo de actividad, lugar de realización, tiempo, duración y frecuencia.

La educación no formal en el museo se centraliza en los programas públicos de acción cultural, en donde los visitantes participan voluntaria y libremente, de acuerdo con sus propios intereses y disponibilidad de tiempo
(García 2013, p. 12). Estos programas se dan debido a la necesidad de adaptar el discurso expositivo a determinados tipos de público o ampliarlo de acuerdo con lo que desean saber, dirigiéndose a segmentos determinados (dependiendo de los contenidos conceptuales en razón de lo que ofrece la exposición o por la dificultad que tienen de acceder a ellos).

Para implementar programas educativos en el ámbito de la educación formal en los museos, es necesario tener en cuenta lo siguiente:

- Conocimientos previos de los estudiantes a nivel curricular.

- Capacidades y habilidades procedimentales.

- Adaptación de los contenidos de las actividades propuestas a los contenidos curriculares de los diversos niveles educativos.

- Adaptación de las actividades al nivel del desarrollo cognitivo y a la capacidad de abstracción de los estudiantes.

Las principales actividades que se desarrollan dentro de la educación formal son las siguientes: recorridos didácticos, visitas teatralizadas, visitas-taller, entre otras.

El programa educativo para la educación no formal contempla un público más amplio, debido a que no solo se limita a los estudiantes sino se orientan a un segmento específico de público, donde estos van a los museos por propia voluntad en su tiempo libre y/o por diversos motivos como disfrutar de un ambiente especial, entre otras.

Las actividades más habituales que se desarrollan en relación con la educación no formal son las siguientes: visitas guiadas, visitas participativas, visitas singulares, visitas autogestionadas, visitas teatralizadas, visitas-taller, entre otras. 


\section{Guion pedagógico y contenidos educativos}

\begin{tabular}{|c|c|c|c|c|c|c|}
\hline \multirow{2}{*}{ CONTENIDO } & \multirow{2}{*}{ PROPÓSITO } & \multicolumn{3}{|c|}{ COMPETENCIAS } & \multirow{2}{*}{$\begin{array}{l}\text { ACTIVIDADES } \\
\text { EN EL MUSEO }\end{array}$} & \multirow{2}{*}{$\begin{array}{c}\text { RECURSOS } \\
\text { EN EL } \\
\text { MUSEO }\end{array}$} \\
\hline & & CONCEPTUAL & PROCEDIMENTAL & ACTITUDINAL & & \\
\hline \multirow[b]{2}{*}{$\begin{array}{c}\text { PRIMER } \\
\text { UMBRAL } \\
\text { ORIGEN DE } \\
\text { LA } \\
\text { AMAZONÍA } \\
\text { ANDINA }\end{array}$} & \multirow{2}{*}{$\begin{array}{c}\text { Ser capaz de } \\
\text { generar } \\
\text { pensamiento } \\
\text { crítico, } \\
\text { reflexivo y } \\
\text { creativo en } \\
\text { torno al origen } \\
\text { de la Amazonía } \\
\text { andina. } \\
\text { Desarrollar las } \\
\text { habilidades de } \\
\text { los niños, } \\
\text { jóvenes, } \\
\text { adultos y adulto } \\
\text { mayor para } \\
\text { comprender y } \\
\text { apreciar el } \\
\text { patrimonio } \\
\text { natural } \\
\text { amazónico } \\
\text { entendiendo su } \\
\text { origen y } \\
\text { procesos de } \\
\text { transformación. }\end{array}$} & $\begin{array}{c}\text { Los estudiantes } \\
\text { y público } \\
\text { visitante del } \\
\text { museo se } \\
\text { familiarizan } \\
\text { con los temas } \\
\text { propuestos en } \\
\text { el umbral. } \\
\end{array}$ & $\begin{array}{l}\text { Los estudiantes } \\
\text { son capaces de } \\
\text { expresarse e } \\
\text { interpretar los } \\
\text { distintos bienes } \\
\text { culturales } \\
\text { expuestos en la } \\
\text { sala a partir del } \\
\text { empleo de una } \\
\text { serie de técnicas } \\
\text { artísticas, lúdicas y } \\
\text { pedagógicas. }\end{array}$ & \multirow{2}{*}{$\begin{array}{l}\text { Los estudiantes } \\
\text { y público } \\
\text { visitante del } \\
\text { museo luego de } \\
\text { conocer y } \\
\text { reflexionar } \\
\text { sobre el origen } \\
\text { de la Amazonía } \\
\text { valoran la } \\
\text { diversidad } \\
\text { natural y } \\
\text { generan interés } \\
\text { en protegerla. }\end{array}$} & \begin{tabular}{|c|} 
Actividades \\
que se \\
desarrollan \\
dentro de la \\
educación \\
formal: \\
itinerarios \\
específicos, \\
visitas \\
teatralizadas, \\
monólogo, \\
visitas - taller, \\
desarrollo de \\
fichas \\
didácticas, \\
entre otras. \\
\end{tabular} & $\begin{array}{c}\text { Réplicas de } \\
\text { los } \\
\text { dinosaurios } \\
\text { a escala } \\
\text { natural, } \\
\text { infografías y } \\
\text { dioramas }\end{array}$ \\
\hline & & $\begin{array}{l}\text { Los estudiantes } \\
\text { y público } \\
\text { visitante del } \\
\text { museo luego de } \\
\text { conocer los } \\
\text { contenidos del } \\
\text { umbral } \\
\text { desarrollan la } \\
\text { capacidad de } \\
\text { ordenar, } \\
\text { interpretar y } \\
\text { relacionar sus } \\
\text { conocimientos } \\
\text { sobre el medio } \\
\text { ambiente y el } \\
\text { origen de la } \\
\text { Amazonía } \\
\text { andina. }\end{array}$ & $\begin{array}{l}\text { Los estudiantes } \\
\text { aprenden a } \\
\text { emplear las } \\
\text { distintas técnicas } \\
\text { artísticas con la } \\
\text { finalidad de } \\
\text { expresar sus } \\
\text { sentimientos e } \\
\text { ideas a propósito } \\
\text { de su relación con } \\
\text { el origen de la } \\
\text { Amazonía. }\end{array}$ & & \begin{tabular}{|c|} 
Actividades \\
relacionadas \\
con la \\
educación no \\
formal: visitas \\
guiadas, visitas \\
participativas, \\
visitas \\
singulares, \\
visitas \\
teatralizadas, \\
así como \\
talleres \\
artísticos y \\
culturales \\
donde los \\
alumnos \\
aprenden a \\
expresarse de \\
forma lúdica \\
y/o estética.
\end{tabular} & $\begin{array}{c}\text { Réplicas de } \\
\text { los } \\
\text { dinosaurios } \\
\text { a escala } \\
\text { natural, } \\
\text { infografías y } \\
\text { dioramas. }\end{array}$ \\
\hline
\end{tabular}




\section{Guion pedagógico y contenidos educativos}

\begin{tabular}{|c|c|c|c|c|c|c|}
\hline \multirow{2}{*}{ CONTENIDO } & \multirow{2}{*}{ PROPÓSITO } & \multicolumn{3}{|c|}{ COMPETENCIAS } & \multirow{2}{*}{$\begin{array}{l}\text { ACTIVIDADES } \\
\text { EN EL MUSEO }\end{array}$} & \multirow{2}{*}{$\begin{array}{c}\text { RECURSOS } \\
\text { EN EL } \\
\text { MUSEO }\end{array}$} \\
\hline & & CONCEPTUAL & PROCEDIMENTAL & ACTITUDINAL & & \\
\hline \multirow[b]{2}{*}{$\begin{array}{c}\text { SEGUNDO } \\
\text { UMBRAL: } \\
\text { DIVERSIDAD } \\
\text { AMBIENTAL } \\
\text { Y CULTURAL } \\
\text { EN LA } \\
\text { AMAZONÍA } \\
\text { ANDINA }\end{array}$} & \multirow{2}{*}{$\begin{array}{l}\text { Ser capaz de } \\
\text { generar } \\
\text { pensamiento } \\
\text { crítico, } \\
\text { reflexivo y } \\
\text { creativo sobre } \\
\text { la diversidad } \\
\text { ambiental y } \\
\text { cultural de la } \\
\text { Amazonía } \\
\text { andina. } \\
\text { Desarrollar las } \\
\text { habilidades de } \\
\text { los niños y } \\
\text { público en } \\
\text { general para } \\
\text { comprender y } \\
\text { apreciar el } \\
\text { patrimonio } \\
\text { natural la } \\
\text { cultura material } \\
\text { e inmaterial de } \\
\text { las diferentes } \\
\text { comunidades } \\
\text { amazónicas, } \\
\text { generando } \\
\text { conciencia } \\
\text { ecológica, } \\
\text { tolerancia, } \\
\text { respeto y } \\
\text { valoración de } \\
\text { la diversidad } \\
\text { cultural. }\end{array}$} & \begin{tabular}{|c|} 
Los estudiantes \\
y público \\
visitante del \\
museo \\
aprenden sobre \\
la importancia \\
de la \\
cosmovisión de \\
los diferentes \\
pueblos \\
amazónicos y \\
sus costumbres \\
reflejadas en su \\
arte y objetos \\
culturales. \\
\end{tabular} & \begin{tabular}{|c} 
Los estudiantes \\
son capaces de \\
expresarse e \\
interpretar los \\
distintos objetos \\
de la sala a partir \\
del empleo de una \\
serie de técnicas \\
artísticas y \\
pedagógicas \\
\end{tabular} & \multirow{2}{*}{\begin{tabular}{|c|} 
Los estudiantes \\
y público \\
visitante del \\
museo luego de \\
conocer y \\
reflexionar \\
sobre la riqueza \\
cultural y \\
biológica de la \\
Amazonía \\
valoran la \\
diversidad \\
cultural del \\
Perú y se \\
preocuparán \\
por protegerla.
\end{tabular}} & $\begin{array}{c}\text { Actividades } \\
\text { que se } \\
\text { desarrollan } \\
\text { dentro de la } \\
\text { educación } \\
\text { formal: } \\
\text { recorridos } \\
\text { didácticos, } \\
\text { visitas } \\
\text { teatralizadas, } \\
\text { monólogo } \\
\text { teatralizado, } \\
\text { visitas-taller, } \\
\text { entre otras. }\end{array}$ & $\begin{array}{c}\text { Instalación } \\
\text { interactiva: } \\
\text { La Madre de } \\
\text { la Floresta } \\
\text { Mariposario } \\
\text { Acuario. } \\
\text { Mesa } \\
\text { interactiva } \\
\text { táctil }\end{array}$ \\
\hline & & \begin{tabular}{|c|} 
\\
\\
Los estudiantes \\
y público \\
visitante del \\
museo \\
aprenden sobre \\
la naturaleza de \\
la diversidad de \\
flora y fauna en \\
el territorio \\
amazónico. \\
\end{tabular} & \begin{tabular}{|c|} 
Los estudiantes \\
aprenden a \\
emplear las \\
distintas técnicas \\
artísticas con la \\
finalidad de \\
expresar sus \\
sentimientos e \\
ideas a propósito \\
de su relación con \\
la Amazonía.
\end{tabular} & & \begin{tabular}{|} 
Actividades \\
relacionadas \\
con la \\
educación no \\
formal: visitas \\
guiadas, visitas \\
participativas, \\
visitas \\
singulares, \\
visitas \\
teatralizadas, \\
así como \\
talleres \\
artísticos y \\
culturales \\
donde los \\
alumnos \\
aprenden a \\
expresarse de \\
forma lúdica y \\
estética.
\end{tabular} & $\begin{array}{l}\text { Instalación } \\
\text { interactiva } \\
\text { La Madre de } \\
\text { la Floresta } \\
\text { Mesa } \\
\text { interactiva } \\
\text { táctil }\end{array}$ \\
\hline
\end{tabular}




\section{Guion pedagógico y contenidos educativos}

\begin{tabular}{|c|c|c|c|c|c|c|}
\hline \multirow{2}{*}{ CONTENIDO } & \multirow{2}{*}{ PROPÓSITO } & \multicolumn{3}{|c|}{ COMPETENCIAS } & \multirow{2}{*}{$\begin{array}{l}\text { ACTIVIDADES } \\
\text { EN EL MUSEO }\end{array}$} & \multirow{2}{*}{$\begin{array}{c}\text { RECURSOS EN } \\
\text { EL MUSEO }\end{array}$} \\
\hline & & CONCEPTUAL & PROCEDIMENTAL & ACTITUDINAL & & \\
\hline \multirow[t]{2}{*}{$\begin{array}{c}\text { TERCER } \\
\text { UMBRAL: LOS } \\
\text { PROCESOS } \\
\text { HISTÓRICOS }\end{array}$} & \multirow{2}{*}{$\begin{array}{c}\text { Ser capaz de } \\
\text { generar } \\
\text { pensamiento } \\
\text { crítico, reflexivo } \\
\text { y creativo. } \\
\text { Desarrollar las } \\
\text { habilidades de } \\
\text { los estudiantes y } \\
\text { público en } \\
\text { general para } \\
\text { comprender y } \\
\text { apreciar los } \\
\text { procesos } \\
\text { históricos de la } \\
\text { Amazonía. Esto } \\
\text { implica el } \\
\text { conocimiento de } \\
\text { los personajes, } \\
\text { el largo proceso } \\
\text { de } \\
\text { interculturalidad. }\end{array}$} & \begin{tabular}{|} 
Los estudiantes \\
y público \\
visitante del \\
museo se \\
familiarizan \\
con los ejes \\
temáticos: la \\
irrupción de la \\
cruz y la \\
irrupción de la \\
espada, la \\
época del \\
caucho, el \\
crecimiento \\
urbano.
\end{tabular} & $\begin{array}{l}\text { Los estudiantes y } \\
\text { público visitante } \\
\text { del museo son } \\
\text { capaces de } \\
\text { expresarse e } \\
\text { interpretar los } \\
\text { distintos objetos } \\
\text { de la sala a partir } \\
\text { del empleo de una } \\
\text { serie de técnicas } \\
\text { artísticas y } \\
\text { pedagógicas } \\
\text { estructuradas a } \\
\text { partir de } 4 \text { grupos } \\
\text { etáreos: educación } \\
\text { infantil, primaria, } \\
\text { secundaria, técnico } \\
\text { y universitario, así } \\
\text { como adultos y } \\
\text { adulto mayor. }\end{array}$ & \multirow{2}{*}{$\begin{array}{c}\text { Los } \\
\text { estudiantes y } \\
\text { público } \\
\text { visitante del } \\
\text { museo luego } \\
\text { de conocer y } \\
\text { reflexionar } \\
\text { sobre los } \\
\text { procesos } \\
\text { históricos de } \\
\text { la Amazonía } \\
\text { andina } \\
\text { tendrán mayor } \\
\text { interés por } \\
\text { investigar su } \\
\text { pasado, } \\
\text { respeto y } \\
\text { sentido de } \\
\text { justicia hacia } \\
\text { las } \\
\text { comunidades } \\
\text { amazónicas. }\end{array}$} & $\begin{array}{l}\text { Actividades } \\
\text { que se } \\
\text { desarrollan } \\
\text { dentro de la } \\
\text { educación } \\
\text { formal: } \\
\text { recorridos } \\
\text { didácticos, } \\
\text { visitas } \\
\text { teatralizadas, } \\
\text { monólogo } \\
\text { teatralizado, } \\
\text { visitas-taller, } \\
\text { entre otras. }\end{array}$ & $\begin{array}{c}\text { Réplicas de } \\
\text { bienes } \\
\text { culturales, } \\
\text { infografías, } \\
\text { instalaciones, } \\
\text { mesa interactiva } \\
\text { táctil. } \\
\text { Sensaciones a } \\
\text { través de } \\
\text { sonidos, olores. } \\
\text { Instalación la } \\
\text { Madre de la } \\
\text { Floresta. }\end{array}$ \\
\hline & & $\begin{array}{c}\text { Los estudiantes } \\
\text { y público } \\
\text { visitante del } \\
\text { museo luego de } \\
\text { conocer los } \\
\text { contenidos del } \\
\text { umbral } \\
\text { desarrollan la } \\
\text { capacidad de } \\
\text { ordenar, } \\
\text { interpretar y } \\
\text { relacionar sus } \\
\text { conocimientos } \\
\text { con aquellos } \\
\text { propuestos en } \\
\text { los distintos } \\
\text { umbrales. }\end{array}$ & $\begin{array}{l}\text { Los estudiantes y } \\
\text { público visitante } \\
\text { aprenden a } \\
\text { emplear las } \\
\text { distintas técnicas } \\
\text { artísticas con la } \\
\text { finalidad de } \\
\text { expresar sus } \\
\text { sentimientos e } \\
\text { ideas a propósito } \\
\text { de su relación con } \\
\text { la Amazonía. }\end{array}$ & & $\begin{array}{c}\text { Actividades } \\
\text { relacionadas } \\
\text { con la } \\
\text { educación no } \\
\text { formal: visitas } \\
\text { guiadas, visitas } \\
\text { participativas, } \\
\text { visitas } \\
\text { singulares, } \\
\text { visitas } \\
\text { teatralizadas, } \\
\text { así como } \\
\text { talleres } \\
\text { artísticos y } \\
\text { culturales } \\
\text { donde los } \\
\text { alumnos } \\
\text { aprenden a } \\
\text { expresarse de } \\
\text { forma lúdica y } \\
\text { estética. }\end{array}$ & $\begin{array}{c}\text { Réplicas de } \\
\text { bienes } \\
\text { culturales, } \\
\text { materiales } \\
\text { didácticos } \\
\text { (escritos, } \\
\text { audiovisuales o } \\
\text { informáticos). } \\
\text { Instalación la } \\
\text { Madre de la } \\
\text { Floresta. }\end{array}$ \\
\hline
\end{tabular}


Los instrumentos de acción didáctica que se emplearían en el Museo Nacional Amazónico deben hacer uso de los diferentes instrumentos de acción educativa, los cuales deben innovarse cada año a fin de poder tener no solo una amplia oferta de recursos didácticos sino para estar al día con los cambios de la currícula educativa, de las nuevas exposiciones y las nuevas tecnologías.

Tabla 1

Instrumentos básicos de la acción didáctica.

\begin{tabular}{|c|c|}
\hline \multicolumn{2}{|c|}{ Instrumentos básicos de la acción didáctica } \\
\hline Acciones/actividades & Recursos \\
\hline 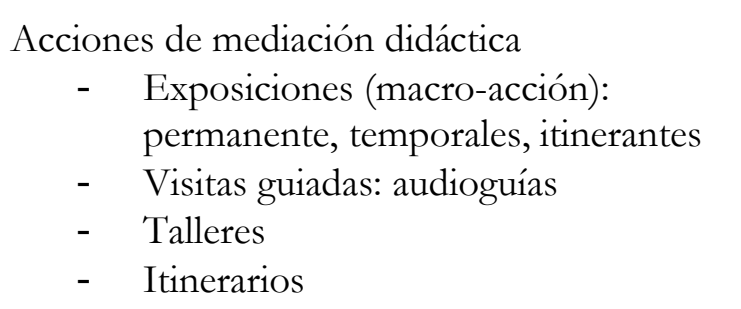 & $\begin{array}{ll}\text { Recursos organizativos } \\
-\quad \text { DEAC } \\
-\quad \text { Documentos institucionales de } \\
\\
\quad \text { regulación de la acción didáctica } \\
(\text { PEM })\end{array}$ \\
\hline $\begin{array}{l}\text { Acciones de formación } \\
-\quad \text { Formación externa } \\
\text { - } \quad \text { Formación interna }\end{array}$ & $\begin{array}{l}\text { Recursos humanos } \\
\text { - Educadores especializados, } \\
\text { mediadores } \\
\text { - Técnicos en elaboración y diseño de } \\
\text { acciones y recursos didácticos } \\
\text { - Maestros bilingües } \\
\text { - Auxiliares }\end{array}$ \\
\hline $\begin{aligned} & \text { Acciones complementarias } \\
& \text { - } \text { Conciertos } \\
& \text { - } \text { Concursos y premios } \\
& \text { - } \text { Espectáculos: obras teatrales, } \\
& \text { dramatizaciones, etc. } \\
&- \\
&\end{aligned}$ & $\begin{array}{l}\text { Recursos funcionales } \\
\text { - Espacios (biblioteca, talleres, } \\
\text { laboratorios, auditorio, sala } \\
\text { audiovisual, archivo, aulas } \\
\text { didácticas) }\end{array}$ \\
\hline $\begin{array}{c}\text { Acciones derivadas de la función didáctica } \\
\text { - } \quad \text { Acuerdo con otras instituciones para } \\
\text { - } \quad \text { el desarrollo de proyectos específicos } \\
\text { - } \quad \text { Colaborios de desarrollo profesional en proyectos y } \\
\text { subvenciones }\end{array}$ & $\begin{array}{l}\text { Recursos materiales } \\
\text { - } \quad \text { De información. Exposición y } \\
\text { materiales educativos }{ }^{3} \text { y didácticos }\end{array}$ \\
\hline
\end{tabular}

3 Materiales pedagógicos que permiten el aprendizaje de los estudiantes, siempre que estén elaborados con pertinencia cultural (conocimiento, tecnología, cosmovisión) y lingüística. Los materiales a desarrollarse (por parte del museo y en estrecha colaboración y asesoramiento del Ministerio de Educación), deben permitir que los estudiantes del mismo pueblo y de otros pueblos conozcan y valoren su cultura. 
En el proceso de educación en el museo, los actores, todos hablantes de la lengua originaria y representantes de sus distintas variedades. Entre estos actores, tenemos a los siguientes:

- Dirigentes de organizaciones indígenas regionales y locales.

- Maestros bilingües.

- Representantes de comunidades y asociaciones de padres de familia.

- Lingüistas especializados en la lengua originaria.

- Especialistas de las Unidades de Gestión Educativa Local (UGEL), de las
Direcciones Regionales de Educación (DRE) $y$ del MINEDU.

- Líderes indígenas.

- Jefes de las comunidades.

- Estudiantes de institutos superiores y/o universidades.

- Sabios y sabias.

Todos ellos intervendrán positivamente en los programas educativos del museo, los mismos que serán elegidos para exponer determinados temas relacionados con su lengua, su cultura o educación; otros serán intérpretes y traductores de los mensajes del español a la lengua originaria, a fin de que todos entiendan aquello de lo que se está hablando.

\section{Programación arquitectónica}

Para la programación arquitectónica del Museo Nacional Amazónico se han considerado nueve (9) zonas, siendo estas las siguientes:

\begin{tabular}{|l|r|}
\hline \multicolumn{1}{|c|}{ Zonas } & \multicolumn{1}{c|}{ Áreas en m² } \\
\hline Común & 479.25 \\
\hline Exposición e interacción & 9892.50 \\
\hline Administrativa & 625.73 \\
\hline Investigación y publicaciones & 378.68 \\
\hline Conservación, manejo de colecciones y depósitos & 1735.43 \\
\hline Educativa - cultural & 1277.10 \\
\hline Servicios complementarios & 2236.28 \\
\hline Servicios generales & 841.05 \\
\hline Estacionamiento & $4,096.95$ \\
\hline
\end{tabular}

En general, todas las instalaciones propuestas para el Museo Nacional Amazónico que contemplan el cautiverio de animales con fines de educación, investigación y difusión se proyectarán en concordancia con los códigos deontológicos correspondientes, y tomando en consideración todas las condiciones físicas, naturales y biológicas para que se pueda generar un ecosistema que no perjudique el natural desarrollo de las especies a exhibirse. Los espacios serán amplios de acuerdo a los requerimientos de cada especie, y habrá un correcto control de la natalidad y la reproducción para garantizar la permanencia de las especies y contribuir además a la conservación de la diversidad biológica de la Amazonía.

\section{Acuario}

El río es el ecosistema que tiene mayor protagonismo en la selva peruana. Inclusive sus variaciones estacionales han marcado históricamente la configuración de sus centros poblados y le confieren a la Amazonía un carácter orgánico que lo hace único. Los ríos amazónicos albergan una flora y fauna muy rica $y$ diversa, y son la fuente de recursos para la alimentación entre otros beneficios. Esta diversidad natural y biológica que albergan se pretende mostrar en un área amplia de acuarios que muestren las principales especies marinas, en concordancia con los principios de 
conservación de los recursos naturales y los códigos de deontología respectivos a la tenencia de animales en cautiverio. El principal objetivo de esta exposición es generar una experiencia vivencial en el visitante al tiempo que conoce $e$ identifica las principales especies típicas de agua dulce.

\section{Mariposario}

Las características físico geográficas de la Amazonía peruana han dado lugar a la presencia de una gran cantidad y variedad de mariposas, diversidad cuya conservación viene poniéndose en riesgo por el alto índice de explotación informal y descontrolada. Son más de 3,700 especies que se pueden identificar en el río Amazonas. El proyecto de mariposario tiene como objetivo mostrar esta variedad de especies en su entorno natural $y$ permitir diseñar e implementar un plan de manejo para la protección y conservación de las especies, y a la par llevar a cabo una labor de investigación, registro y difusión de las mariposas locales.

\section{Insectario}

La diversidad biológica en la región amazónica incluye también una gran cantidad y diversidad de insectos que son parte fundamental del ecosistema amazónico. Por lo general, los insectos se encuentran en gran abundancia en todos los bosques tropicales del mundo, la selva Amazónica es uno de ellos, y alberga tal diversidad que no se puede asegurar la existencia de un registro final y fidedigno de la cantidad de especies de insectos que habitan la selva. Por otro lado, los insectos, por ser pequeños pocas veces se les brinda la importancia que les corresponde para la conservación y funcionamiento del ecosistema, y el rol que cumplen para lograr el equilibrio natural. Por ello, esta colección de insectos pretende posicionar el importante papel que tienen y cumplir un rol educativo $y$ científico, difundiendo además su papel en la gastronomía regional.

\section{Serpentario}

Las serpientes en la región amazónica son representativas y presentan una gran variedad entre venenosas y no venenosas. Su vida en cautiverio debe estar orientada a la conservación y preservación, pues las serpientes son animales muy delicados. El serpentario tendrá como finalidad mostrar las especies predominantes de la selva amazónica $y$, de esta manera, evitar la caza indiscriminada con fines de turismo, presentando un espacio en el cual se las pueda apreciar y aprender de sus cualidades y características, y la importancia de ellas para las culturas amazónicas, no solo en cuanto a alimentación o uso de su piel, sino para la construcción de la memoria colectiva que se compone a partir de historias $y$ mitos vinculados con estos animales.

El serpentario contendrá especies venenosas $y$ no venenosas, con un control adecuado para evitar el envenenamiento y con una selección especializada de especies evitando afectar los ciclos de vida de cada una de ellas. Se priorizará la presencia de especies en riesgo para contribuir al repoblamiento en cautiverio.

5. Xiloteca (como jardín botánico - de plantas maderables más representativas) Se presentará un jardín botánico con presencia de los principales árboles maderables de la Amazonía peruana. La deforestación en la selva del Perú principalmente tiene lugar por los fines comerciales de la madera. La selva en ese sentido es una región depositaria de las especies vegetales más pedidas en el ámbito mercantil. Por ello, es de suma importancia dar a conocer a la comunidad el rol fundamental que tienen las especies maderables para la conservación del ecosistema y por lo tanto la importancia de su conservación y explotación controlada. Por otro lado, se busca mostrar la diversidad 
y características de las especies asociadas además al conocimiento de las comunidades nativas para su identificación y su uso, como parte del rescate y conservación del patrimonio intangible de la Amazonía peruana.

\section{6. Árbol del ecosistema (Aguaje)}

El árbol del ecosistema es la reproducción de un árbol de aguaje en tamaño natural que buscará mostrar de manera didáctica todo el complejo sistema biológico que alberga y propicia un árbol como el aguaje, árbol típico de la selva peruana, tomando en cuenta los procesos de intercambio con otras especies vegetales $y$ animales, $y$ en general, la simbiosis que a manera de muestra tiene lugar en un árbol y también se replica a gran escala en toda la Amazonía.

El "árbol del ecosistema" es un recurso museográfico que pretende a partir de un elemento mostrar el complejo sistema ecológico que tiene lugar en la Amazonía $y$ en donde intervienen diversas especies animales y vegetales y por supuesto los otros recursos que brinda la naturaleza (la tierra, el agua, etc.).

\section{Criadero de paiche}

El Museo Nacional Amazónico incluirá un criadero de paiche como espacio de investigación y conservación de una de las especies hidrográficas más importantes de la selva peruana, como espacio en donde se muestren las tecnologías utilizadas en estos procesos y se difundan los procesos completos, desde los sistemas de producción, la nutrición y alimentación del paiche, su reproducción y genética, su salud, y el rol que tiene el paiche en la economía regional. Además, este espacio servirá para la capacitación tecnológica especializada.

En el criadero de paiche se podrá tener una experiencia vivencial, siempre contando con los controles respectivos para su conservación.

\section{Conclusiones}

Es necesario considerar que el Museo Nacional Amazónico, por la envergadura de la propuesta y sus dimensiones, se plantea que exista un centro de conservación y restauración del material cultural de la Amazonía, es decir que realice labores de custodia; inventario, registro y catalogación; conservación y restauración; e investigación.

El material cultural provendría de la Amazonía y del material que se encuentre en las diversas Direcciones Desconcentradas de Cultura del Perú, asimismo colecciones de particulares que deseen depositar su patrimonio en las instalaciones del museo y/o cualquier otro tipo de forma de adquisición de material. 


\section{REFERENCIAS}

Barciela, S., Delgado, R., Demol, A., Lopez, R., Rodriguez, L., Villalobos, C. (2013) Propuesta de Plan Museológico Museo Marítimo de Málaga. Recuperado el 20 de diciembre de 2013 de http:// issuu.com/soniasan1/docs/plan_museologico

Costa, J. (2007) Diseñar para los ojos (2ª Ed.). La Paz, Bolivia: Grupo Editorial Design.

Dirección General de Educación Intercultural, Bilingüe y Rural, Ministerio de Educación (2013) "Ahora, con estas letras vamos a andar". Sistematización del proceso de normalización de los alfabetos de las lenguas originarias del Perú. Lima. Perú.

Lord, B., Lord, G. (2005) Manual de Gestión de Museos. Barcelona, España: Ariel S.A.

Fernández, C. (1996) Montaje y funciones del laboratorio de conservación y Restauración en museos de arqueología. Recuperado el 10 de noviembre de 2013 de: http://www.uam.es/otros/ cupauam/pdf/Cupauam23/2301.pdf

Fontal Merillas, Olaia (2004) La educación patrimonial: Teoría y práctica en el aula, el museo e internet. Ed. Trea. Barcelona. España.

Ministerio de Cultura, (2013) Estudio de programación museológica y arquitectónica. Propuesta de perfil. Lima. Perú: Ministerio de Cultura.

Ministerio de Cultura, (2012) Lineamientos de Política Cultural 2013 - 2016. Lima. Perú: Ministerio de Cultura.

Ministerio de Cultura (Colombia), Museo Nacional de Colombia (2002) Manual básico de conservación preventiva. Bogotá. Recuperado el 5 de abril del 2012 en: http:/www.ilam.org/viejo/ ILAMDOC/sobi/Manual\%20basico\%20de\%20Conservacion\%20Preventiva-Cons.pdf

Ministerio de Cultura (España), Subdirección General de Publicaciones, Información y Documentación (2006) Criterios para la elaboración del Plan Museológico. Madrid, España: Secretaria General Técnica.

Santacana Mestre, Joan y Núria Serrat Antolí (Coords.) (2007) Museografía didáctica, Ed. Ariel, Barcelona. España.

WWF-Perú (2013) 10 años en el abanico del Pastaza. Naturaleza, culturas y retos en la Amazonía norte peruana. Lima, Perú: Grambs Corporación gráfica.

Fecha de recepción: 25-09-17

Fecha de aceptación: 27-11-17 